\title{
Effects of preoperative aspirin and clopidogrel therapy on perioperative blood loss and blood transfusion requirements in patients undergoing off-pump coronary artery bypass graft surgery
}

Jae Kwang Shim, MD, ${ }^{a}$ Yong Seon Choi, MD, ${ }^{a}$ Young Jun Oh, MD, a,b Sou Ouk Bang, MD, a,b Kyung Jong Yoo, MD, PhD, ${ }^{c, d}$ and Young Lan Kwak, MD, PhD a,b,d

From the Department of Anesthesiology and Pain Medicine, ${ }^{\mathrm{a}}$ the Anesthesia and Pain Research Institute, ${ }^{\mathrm{b}}$ the Department of Thoracic and Cardiovascular Surgery, ${ }^{\mathrm{c}}$ and the Yonsei Cardiovascular Research Institute, ${ }^{\mathrm{d}}$ Yonsei University College of Medicine, Seoul, South Korea.

Received for publication Nov 17, 2006; revisions received March 2, 2007; accepted for publication March 15, 2007.

Address for reprints: Young Lan Kwak, $\mathrm{MD}, \mathrm{PhD}$, Department of Anesthesiology and Pain Medicine and Anesthesia and Pain Research Institute, Yonsei University College of Medicine, 134 Shinchon-Dong, Seodaemun-Ku, Seoul, South Korea, 120725 (E-mail: ylkwak@yumc.yonsei.ac.kr).

J Thorac Cardiovasc Surg 2007;134:59-64

$0022-5223 / \$ 32.00$

Copyright $(92007$ by The American Association for Thoracic Surgery

doi:10.1016/j.jtcvs.2007.03.013
Objective: Preoperative exposure to clopidogrel and aspirin significantly increases postoperative bleeding in patients undergoing on-pump coronary artery bypass graft surgery. Off-pump coronary bypass grafting has been proposed as an alternative technique to attenuate postoperative bleeding associated with clopidogrel. This study aimed to determine the effects of aspirin and clopidogrel therapy on perioperative blood loss and blood transfusion requirements in off-pump coronary artery bypass grafting.

Methods: One hundred six patients scheduled for off-pump coronary artery bypass grafting were divided into three groups: aspirin and clopidogrel discontinued more than 6 days before surgery (group $1, \mathrm{n}=35$ ), aspirin and clopidogrel continued until 3 to 5 days before surgery (group $2, \mathrm{n}=51$ ), and both medications continued within 2 days of surgery (group $3, n=20$ ). Thromboelastographic tracings were analyzed before induction of anesthesia. Routine coagulation profiles were measured before and after surgery. A cell salvage device was used during surgery and salvaged blood was reinfused. Chest tube drainage and blood transfusion requirement were recorded postoperatively.

Results: Patient characteristics, operative data, and thromboelastographic tracings were similar among the groups. There were significant decreases in hematocrit level and platelet count and prolongation in prothrombin time postoperatively in all groups without any intergroup differences. The amounts of perioperative blood loss and blood transfusion required were all similar among the groups.

Conclusion: Preoperative clopidogrel and aspirin exposure even within 2 days of surgery does not increase perioperative blood loss and blood transfusion requirements in patients undergoing elective off-pump coronary artery bypass grafting.

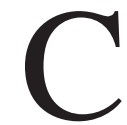

lopidogrel is an irreversible adenosine $5^{\prime}$ disphosphate receptor antagonist that provides potent antiaggregant effect on platelets. ${ }^{1,2}$ The enhanced antiplatelet therapy provided by clopidogrel has led to its use in combination with aspirin as the gold standard for prevention of intracoronary stent thrombosis. ${ }^{3,4}$ In addition, favorable results regarding prevention of recurrent ischemic events leading to reduced risk of cardiovascular morbidity and mortality have been demonstrated by large multicenter trials in patients with coronary artery occlusive disease receiving clopidogrel. ${ }^{5,6}$

As the indications for clopidogrel expand, an increasing percentage of patients referred for coronary artery bypass graft surgery (CABG) are subjected to irreversible platelet inhibition. In conjunction, a number of studies have demonstrated increased procedural bleeding, blood transfusion requirement, and the need for 

Abbreviations and Acronyms
aPTT = activated partial thromboplastin time
$\mathrm{CABG}=$ coronary artery bypass graft
$\mathrm{FFP}=$ fresh frozen plasma
ICU = intensive care unit
MI = myocardial infarction
$\mathrm{pRBCs}=$ packed red blood cells
$\mathrm{PT}=$ prothrombin time
$\mathrm{SD} \quad=$ standard deviation

surgical re-exploration related to clopidogrel in patients undergoing conventional on-pump $\mathrm{CABG},{ }^{7-10}$ prompting suggestions to delay the operation or transfuse platelets perioperatively. However, caution should be exercised, weighing the risk of postoperative blood loss and its sequelae and the clinical benefits of sustained antiplatelet therapy in preventing graft occlusion and ischemic complications. ${ }^{11,12}$

Off-pump CABG is associated with significantly reduced rates of postoperative bleeding and blood transfusion requirements, presumably in part because of avoidance of cardiopulmonary bypass-induced blood component dilution and dysfunction. ${ }^{13}$ Therefore, it has been proposed as an alternative surgical technique to reduce postoperative bleeding in patients with coronary artery occlusive disease who have recent exposure to antiplatelet therapy. ${ }^{14,15}$ Yet, these studies demonstrate conflicting results and were either preliminary or retrospective, lacking statistical power or risk adjustment between the groups. ${ }^{10,16,17}$

We therefore evaluated the influence of preoperative combined aspirin and clopidogrel medication on perioperative blood loss and blood transfusion requirements in patients undergoing elective off-pump CABG in a prospective trial.

\section{Patients and Methods}

After institutional review board approval and surrogate informed consent were obtained, patients scheduled for isolated mutivessel off-pump CABG between November 2005 and August 2006 were studied. Patients undergoing emergency surgery and those with a history of previous cardiac surgery, preoperative exposure to warfarin sodium (Coumadin), platelet glycoprotein IIb/IIIa inhibitors, or thrombolytics were excluded. Accordingly, a total of 106 patients were included in the study. The timing of discontinuation of antiplatelet medications was at the discretion of the cardiologists rather than dictated by the protocol.

Patients were divided into three groups according to their medication history: patients whose aspirin and clopidogrel were discontinued more than 6 days before surgery (group $1, \mathrm{n}=35$ ), patients who received a daily oral regimen of $100 \mathrm{mg}$ of aspirin and $75 \mathrm{mg}$ of clopidogrel until 3 to 5 days before surgery (group $2, \mathrm{n}=51$ ), and patients who continued both medications within 2 days of surgery (group $3, \mathrm{n}=20$ ). The subdivisions at 5 and 2 days were according to the recent American College of Cardiology/ American Heart Association recommendation and to the rate of replacement of exposed platelets by new platelets, respectively. ${ }^{18-20}$ All other cardiovascular medications except diuretics were continued until the day of the operation.

All patients received 0.05 to $0.1 \mathrm{mg} / \mathrm{kg}$ of morphine intramuscularly as premedication 1 hour before the operation. On the patient's arrival at the operating room, standard monitoring devices were applied, including a pulmonary arterial catheter (SwanGanz CCOmbo CCO/SvO2; Edwards Lifesciences, Irvine, Calif), which was inserted through the right internal jugular vein before induction of anesthesia. Anesthesia was induced with intravenous midazolam $(0.05 \mathrm{mg} / \mathrm{kg})$ and sufentanil $(1.5-3.0 \mu \mathrm{g} / \mathrm{kg})$ and was maintained with sevoflurane $(0.8-1.5 \mathrm{vol} / 100 \mathrm{~mL})$ and continuous infusion of sufentanil $\left(0.5-1.5 \mu \mathrm{g} \cdot \mathrm{kg}^{-1} \cdot \mathrm{min}^{-1}\right)$. Neuromuscular blockade was achieved by administering rocuronium bromide (0.9 $\mathrm{mg} / \mathrm{kg}$ ) and maintained with continuous infusion of vecuronium bromide $\left(1-2 \mu \mathrm{g} \cdot \mathrm{kg}^{-1} \cdot \mathrm{min}^{-1}\right)$. After induction of anesthesia, a transesophageal echocardiography probe was inserted to detect newly developing segmental wall motion abnormalities. Isosorbide dinitrate $0.5 \mu \mathrm{g} \cdot \mathrm{kg}^{-1} \cdot \mathrm{min}^{-1}$ was infused in all patients throughout the study period. Intravascular volume replacement was managed with crystalloid and colloid solutions to maintain the pulmonary capillary wedge pressure between 8 and $16 \mathrm{~mm} \mathrm{Hg}$ according to the baseline values. Central temperature, as measured by pulmonary arterial catheter, was maintained between $36^{\circ} \mathrm{C}$ and $37^{\circ} \mathrm{C}$ with a warm mattress, forced warm air blanket, and fluid warmer as necessary.

All surgical procedures were performed by one surgeon through a median sternotomy, and the heart was displaced with a posterior pericardial stitch, large $(12 \times 70 \mathrm{~cm})$ gauze swabs, and tissue stabilizer (Octopus Tissue Stabilization System; Medtronic Inc, Minneapolis, Minn). Systemic heparinization during anastomoses was achieved with $150 \mathrm{U} / \mathrm{kg}$ of porcine heparin with additional doses to reach the target activated clotting time greater than 300 seconds. On completion of anastomoses, heparin activity was neutralized with protamine sulfate $(0.5 \mathrm{mg} / 150 \mathrm{U}$ of heparin). A cell salvage device was used during the operation in all cases and salvaged blood was reinfused to the patient before the end of the operation. None of the patients received antifibrinolytics throughout the study period. All patients were transferred to the intensive care unit (ICU) after the operation.

Allogenic packed red blood cells (pRBCs) were transfused when the hematocrit level was less than $25 \%$ for patients 65 years of age or older and when the hematocrit level was less than $21 \%$ for patients younger than 65 years of age throughout the study period. Fresh frozen plasma (FFP) was transfused when the postoperative international normalized ratio was greater than 1.5 with excessive bleeding greater than $200 \mathrm{~mL} / \mathrm{h}$ for 2 consecutive hours. The criteria for transfusion of platelets were postoperative platelet count less than $50,000 / \mathrm{mm}^{3}$ with excessive bleeding greater than $200 \mathrm{~mL} / \mathrm{h}$ for 2 consecutive hours. Surgical re-exploration was indicated when chest tube drainage was greater than $200 \mathrm{~mL} / \mathrm{h}$ for 6 consecutive hours or greater than $400 \mathrm{~mL}$ during the first hour despite normalized activated clotting time and global coagulation status.

Hematocrit level, platelet counts, prothrombin time (PT), and activated partial thromboplastin time (aPTT) were measured 24 hours before and after the operation. Thromboelastographic tracings were analyzed before induction of anesthesia to detect other possibly existing coagulation abnormalities between the groups by 
measuring reaction time (r-time), coagulation time (K-time), clot formation rate ( $\alpha$-angle), and clot strength (maximal amplitude) with a 2-channel coagulation analysis system (TEG model 3000; Haemoscope Corp, Niles, Ill). Total number of units of pRBCs, FFP, and platelets given during the postoperative hospitalization period were recorded, including the number of units given during the operation and in the ICU postoperatively. Intraoperative blood loss was recorded as the amount of reinfused salvaged blood by a cell salvage device. Postoperative blood loss was recorded as the volume of chest tube drainage measured at 24 hours after surgery and the drained blood was not reinfused.

Statistical analyses were performed with SPSS 12.0 (SPSS Inc, Chicago, Ill). All data are expressed as number of patients (percentage) or mean $\pm \mathrm{SD}$. A difference of $250 \mathrm{~mL}$ of chest tube drainage between the groups was taken as clinically significant to reduce 1 unit transfusion of pRBCs. We determined that 20 patients would be required in each group with $80 \%$ power and alpha level of .05 to detect a $250-\mathrm{mL}$ difference in postoperative blood loss among the groups with an SD of $250 \mathrm{~mL},{ }^{21,22}$ and with the same power and alpha level to detect 1 unit of pRBC difference in transfusion requirements among the groups in the ICU postoperatively with an SD of 1 unit using analysis of variance. Data between the groups were compared by the $\chi^{2}$ test, Fisher exact test, or 1-way analysis of variance with post hoc comparison using the Bonferroni test as appropriate. Data within the group were compared by the paired $t$ test.

\section{Results}

Off-pump CABG could be successfully performed in all patients, except one conversion to cardiopulmonary bypass in group 2 owing to development of intractable arrhythmia during posterior descending artery grafting. None of the patients had newly developed segmental wall motion abnormalities and postoperative electrocardiographic changes indicative of myocardial infarction (MI). Hemostatic reexploration was performed in 2 patients in group 1 , and both patients had an obvious surgical cause of bleeding. Data for these 3 patients were excluded from statistical analysis. Otherwise, of the included 103 patients, none required hemostatic re-exploration.

There were no significant differences in demographic and operative data including history of MI, preoperative serum creatinine level, left ventricular ejection fraction, number of grafts, and operation time among the groups. The length of stay in the ICU and total length of postoperative hospitalization period were also similar among the groups (Table 1).

Preoperative thromboelastographic variables were comparable among the groups. There were no significant differences in hematocrit level, platelet counts, PT, and aPTT before and after surgery among the groups. Postoperative hematocrit level was significantly decreased and PT was significantly prolonged compared with preoperative values in all three groups (all $P$ values are $<.0001$ ). Postoperative platelet counts were significantly decreased compared with preoperative values in groups 1 and 2 (both $P$ values are $<$ .0001). Postoperative aPTT was significantly prolonged compared with preoperative values in group $3(P=0.004)$ (Table 2).

Total amount of fluid infused and urine output during the operation and first 24 hours in the ICU postoperatively were similar between the groups. There were no significant differences in the amount of re-infused blood salvaged with a cell salvage device in the operating room and postoperative blood loss among the groups (Table 3).

TABLE 1. Patient characteristics, operative data, and duration of hospital admission

\begin{tabular}{|c|c|c|c|c|}
\hline & Group $1(n=33)$ & Group $2(n=50)$ & Group $3(n=20)$ & $P$ value \\
\hline Age (y) & $63.8 \pm 8.7$ & $61.6 \pm 10.3$ & $63.7 \pm 8.4$ & .527 \\
\hline $\operatorname{Sex}(M / F)$ & $24 / 9$ & $41 / 9$ & $16 / 3$ & .503 \\
\hline Height (cm) & $163.2 \pm 8.4$ & $160.8 \pm 8.4$ & $164.6 \pm 7.8$ & .185 \\
\hline Weight (kg) & $64.5 \pm 9.6$ & $65.7 \pm 10.6$ & $65.0 \pm 16.2$ & .884 \\
\hline Body surface area $\left(\mathrm{m}^{2}\right)$ & $1.7 \pm 0.2$ & $1.7 \pm 0.2$ & $1.8 \pm 0.2$ & .449 \\
\hline \multicolumn{5}{|l|}{ Preoperative medication } \\
\hline$\beta$-blockers & $23(70)$ & $38(76)$ & $15(79)$ & .720 \\
\hline ACE inhibitors & $22(66)$ & $33(66)$ & $8(42)$ & .148 \\
\hline Calcium channel blockers & $19(58)$ & $28(56)$ & $13(68)$ & .635 \\
\hline Hypertension & $17(52)$ & $27(54)$ & $13(68)$ & .554 \\
\hline Diabetes mellitus & $12(36)$ & $15(30)$ & $8(42)$ & .483 \\
\hline Creatinine level (mg/dL) & $1.2 \pm 0.8$ & $1.1 \pm 0.7$ & $1.1 \pm 0.3$ & .727 \\
\hline Operation time (min) & $344 \pm 67$ & $363 \pm 97$ & $348 \pm 85$ & .573 \\
\hline No. of grafts & $3.3 \pm 0.7$ & $3.4 \pm 0.8$ & $3.3 \pm 0.9$ & .818 \\
\hline ICU days & $2.9 \pm 0.7$ & $2.8 \pm 0.6$ & $2.7 \pm 0.7$ & .595 \\
\hline Postoperative hospital days & $12.9 \pm 7.0$ & $11.0 \pm 4.1$ & $10.1 \pm 2.2$ & .174 \\
\hline
\end{tabular}

Values are either mean $\pm S D$ or number of patients (percentage). ACE, Angiotensin converting enzyme; ICU days, length of stay in the intensive care unit; postoperative hospital days, length of postoperative hospitalization period including ICU days; $P$ value, intergroup comparison. 
TABLE 2. Hematologic and coagulation profile

\begin{tabular}{|c|c|c|c|c|}
\hline & Group $1(n=33)$ & Group $2(n=50)$ & Group $3(n=20)$ & $P$ value \\
\hline \multicolumn{5}{|l|}{ Hematocrit $(\%)$} \\
\hline Pre & $35.9 \pm 5.7$ & $37.3 \pm 5.3$ & $39.4 \pm 4.5$ & .063 \\
\hline Post & $25.9 \pm 2.5^{*}$ & $24.8 \pm 3.3^{*}$ & $24.1 \pm 2.7^{*}$ & .092 \\
\hline \multicolumn{5}{|l|}{ Prothrombin time (s) } \\
\hline Pre & $12.5 \pm 2.2$ & $12.1 \pm 1.1$ & $11.4 \pm 0.8$ & .071 \\
\hline Post & $14.5 \pm 1.0^{*}$ & $14.6 \pm 2.5^{*}$ & $15.1 \pm 1.6^{*}$ & .772 \\
\hline \multicolumn{5}{|l|}{ aPTT (s) } \\
\hline Pre & $44.6 \pm 20.9$ & $41.8 \pm 16.5$ & $34.7 \pm 7.6$ & .121 \\
\hline Post & $43.2 \pm 9.1$ & $41.5 \pm 10.1$ & $41.9 \pm 8.3^{*}$ & .757 \\
\hline \multicolumn{5}{|l|}{ Platelet count $\left(10^{3} / \mathrm{mm}^{3}\right)$} \\
\hline Pre & $243 \pm 83$ & $226 \pm 79$ & $231 \pm 472$ & .586 \\
\hline Post & $171 \pm 63$ & $150 \pm 65$ & $144 \pm 382$ & .206 \\
\hline \multicolumn{5}{|l|}{ Thromboelastography } \\
\hline Reaction time (mm) & $26.0 \pm 9.6$ & $29.5 \pm 8.1$ & $29.8 \pm 6.9$ & .176 \\
\hline Clotting time (mm) & $10.1 \pm 4.1$ & $11.9 \pm 5.3$ & $12.4 \pm 3.5$ & .200 \\
\hline$\alpha$-angle $\left({ }^{\circ}\right)$ & $41.5 \pm 10.1$ & $37.0 \pm 10.9$ & $33.8 \pm 8.5$ & .056 \\
\hline Maximal amplitude (mm) & $44.6 \pm 6.0$ & $44.1 \pm 8.6$ & $41.9 \pm 7.9$ & .481 \\
\hline
\end{tabular}

Values are mean \pm SD. Pre, Preoperative 1 day; Post, 24 hours postoperatively; aPTT, activated partial thromboplastin time; $P$ value, intergroup comparison; ${ }^{*} P<.05$ compared with preoperative value.

None of the patients received FFP and platelets during the operation. Amounts of transfused FFP in the postoperative period were similar among the groups and were 10 units in 4 patients, 13 units in 4 patients, and 2 units in 1 patient in groups 1, 2 and 3, respectively. Amounts of transfused platelets in the postoperative period were also similar among the groups and were none in group 1 and 8 units in 1 patient each in groups 2 and 3 . A total of 58 patients received pRBCs during the entire postoperative hospitalization period, with 23 patients during the operation and 40 patients in the ICU. The number of patients and total amount of transfused pRBCs were similar among the groups (Table 3).

\section{Discussion}

In this prospective study, continuing clopidogrel and aspirin even within 2 days of surgery did not result in increased

TABLE 3. Perioperative fluid balance and amount of perioperative blood loss and transfusion

\begin{tabular}{|c|c|c|c|c|}
\hline & Group $1(n=33)$ & Group $2(n=50)$ & Group $3(n=20)$ & $P$ value \\
\hline \multicolumn{5}{|c|}{ Fluid input (L) } \\
\hline $\mathrm{OR}$ & $4.4 \pm 0.9$ & $5.0 \pm 1.7$ & $4.7 \pm 1.2$ & .147 \\
\hline ICU24 & $2.9 \pm 1.1$ & $3.1 \pm 0.9$ & $3.4 \pm 1.0$ & .569 \\
\hline \multicolumn{5}{|c|}{ Urine output (mL) } \\
\hline $\mathrm{OR}$ & $1094 \pm 658$ & $963 \pm 539$ & $827 \pm 453$ & .264 \\
\hline ICU24 & $2307 \pm 891$ & $2255 \pm 922$ & $2387 \pm 780$ & .857 \\
\hline \multicolumn{5}{|c|}{ Blood loss (mL) } \\
\hline OR & $265 \pm 146$ & $330 \pm 191$ & $323 \pm 187$ & .174 \\
\hline ICU24 & $756 \pm 408$ & $729 \pm 485$ & $627 \pm 257$ & .425 \\
\hline \multicolumn{5}{|c|}{ pRBC transfusion (units) } \\
\hline $\mathrm{OR}$ & $0.4 \pm 0.5$ & $0.5 \pm 0.5$ & $0.3 \pm 0.4$ & .260 \\
\hline ICU & $0.4 \pm 0.7$ & $0.7 \pm 1.0$ & $0.6 \pm 1.0$ & .512 \\
\hline Total & $1.1 \pm 1.8$ & $1.9 \pm 0.8$ & $1.6 \pm 1.9$ & .386 \\
\hline \multicolumn{5}{|c|}{ No. of patients transfused with pRBC $(\%)$} \\
\hline $\mathrm{OR}$ & $13(39)$ & $24(48)$ & $5(26)$ & .255 \\
\hline ICU & $14(42)$ & $21(42)$ & $5(25)$ & .368 \\
\hline Total & $17(52)$ & $32(64)$ & $9(45)$ & .279 \\
\hline
\end{tabular}

Values are either mean $\pm \mathrm{SD}$ or number of patients (percentage). $p R B C$, Packed red blood cell; $O R$, during the operation; ICU24, during the first 24 hours in the intensive care unit postoperatively; ICU, during admission in the intensive care unit postoperatively; Total, during the postoperative hospitalization period including $\mathrm{OR}$ and ICU; $P$ value, intergroup comparison. 
amount of perioperative blood loss and blood transfusion requirement while applying intraoperative blood salvage technique and strict transfusion guidelines in patients undergoing elective off-pump CABG.

After the encouraging results of Clopidogrel in Unstable angina to prevent Recurrent ischemic Events (CURE) ${ }^{5}$ and Clopidogrel vs. Aspirin in patients at Risk of Ischemic Events (CAPRIE) ${ }^{6}$ trials, which demonstrated reduced risk of cardiovascular death, MI, and cerebrovascular accident in patients with acute coronary syndrome, prophylactic antiplatelet therapy with clopidogrel is being more aggressively prescribed. Clopidogrel was also superior to aspirin alone for prevention of post-CABG ischemic events. ${ }^{23}$ Therefore, increasing numbers of patients with coronary artery occlusive disease are brought to surgery with recent clopidogrel exposure.

Despite the beneficial effect of combined clopidogrel and aspirin medication, especially in patients with ongoing ischemia, concerns have been raised regarding risk of postoperative bleeding and its sequelae in cardiac surgical patients. Increased risk of postoperative bleeding, transfusion, and re-exploration with combined clopidogrel and aspirin in patients having on-pump CABG has been reported in several studies, ${ }^{7-10}$ although excess bleeding associated with clopidogrel predominantly compromised moderate rather than major bleeding in a recent large-scale randomized study. ${ }^{24}$

Owing to avoidance of cardiopulmonary bypass-induced coagulation abnormalities and its association with lower rate of hemorrhagic sequelae, ${ }^{25}$ off-pump CABG may have a role in decreasing postoperative bleeding and its sequelae, thereby eliminating the need to delay surgery in patients exposed to clopidogrel. ${ }^{14,15}$ Indeed, there has been a limited number of studies regarding the relationship between recent clopidogrel and aspirin exposure with postoperative blood loss in off-pump CABG, and the results are contradictory. ${ }^{10,16,17}$ Recently, there was a study evaluating the effect of preoperative clopidogrel on the incidence of hemostatic re-exploration, requirement for blood product transfusion, morbidity, and mortality in patients undergoing off-pump CABG using a large sample size of patients. ${ }^{16}$ In that study, preoperative clopidogrel administration emerged as the single most significant predictive factor for hemostatic re-exploration and blood product transfusion requirements. However, it was a retrospective study without measuring actual postoperative blood loss, and the patients who received clopidogrel had a lower body weight, higher incidence of preoperative MI, and more frequent need for urgent revascularization. Weight is an independent predictor of blood, and preoperative MI and urgent surgery are also widely known risk factors for postoperative blood loss. ${ }^{9,15}$

Bleeding after CABG can be multifactorial, and along with inadequate surgical hemostasis, pre-existing coagula- tion and platelet abnormalities, potential risk factors include age, female gender, weight, diabetes, hypertension, renal insufficiency, left ventricular ejection fraction, history of MI, and preoperative hematocrit values. ${ }^{9,10,15,16}$ To the best of our knowledge, this is the first prospective, controlled study with well-matched known risk factors for postoperative blood loss and coagulation profiles including thromboelastographic tracings among the groups, demonstrating the safety of continued antiplatelet therapy in terms of perioperative blood loss and blood transfusion requirements in patients undergoing off-pump CABG. Also, this is the first study considering the timing of discontinuation of clopidogrel before off-pump CABG. Re-exploration rate tended to be higher for those patients undergoing on-pump CABG within 5 days after the last clopidogrel dose, ${ }^{24,25}$ and the American College of Cardiology/American Heart Association recommended that clopidogrel should be withheld for at least 5 days in patients scheduled for elective CABG surgery. ${ }^{18}$ While in a study evaluating the safe time interval of discontinuation of clopidogrel medication before onpump CABG, discontinuation 3 days before surgery was not associated with significantly increased postoperative bleeding. ${ }^{20}$ We divided the patient groups accordingly and could not observe any significant differences in the amount of perioperative blood loss or blood transfusion requirements among the groups, suggesting that surgery may not be delayed on the basis of antiplatelet therapy in patients scheduled for elective off-pump CABG.

The limitations of this study are as follows. Although this was a prospective study and the patients' characteristics were similar among the groups, the timing of discontinuation of antiplatelet therapy was at the discretion of the cardiologists not aware of this study, rather than dictated by the protocol, and therefore the patients could not be randomized. Also, the surgeon was not blinded to the antiplatelet regimen. In addition, we did not compare the weight of the blood-soaked and dry gauzes and tapes applied during the operations, and the amount of unmeasured intraoperative blood loss might have been greater in groups 2 and 3 . Finally, this study may not be sufficiently powered with regard to amount of postoperative blood loss because the largest actual SD was larger than the SD we used for sample size calculation. However, the $P$ value for intergroup comparison of postoperative blood loss was .425 and the mean and SD values were actually the lowest in group 3, which consists of patients who were exposed to clopidogrel and aspirin within 2 days of surgery. Furthermore, there were no significant differences in the subsequent transfusion requirement of pRBC among the groups, especially during the immediate postoperative period in the ICU, with enough statistical power.

In conclusion, preoperative clopidogrel and aspirin therapy did not result in increased perioperative blood loss and 
blood transfusion requirements in patients undergoing elective off-pump CABG. Therefore, instead of delaying surgery unnecessarily, off-pump CABG may be considered as an alternative technique in patients receiving potent antiplatelet therapy. Furthermore, regarding the increased procoagulant activity after off-pump $\mathrm{CABG}^{26}$ and the clinical benefits of sustained antiplatelet therapy in preventing graft occlusion and ischemic complications, ${ }^{11,12,23}$ we suggest continuing appropriate antiplatelet therapy in patients scheduled for elective off-pump CABG.

\section{References}

1. Kam PC, Nethery CM. The thienopyridine derivatives pharmacology and clinical developments. Anaesthesia. 2003;58:28-35.

2. Steinhubl SR, Berger PB, Mann JT 3rd, Fry ET, DeLago A, Wilmer C, et al. Early and sustained oral antiplatelet therapy following percutaneous coronary intervention: a randomized controlled trial. JAMA. 2002;288:2411-20.

3. CLASSICS investigators. Double-blind study of the safety of clopidogrel with and without a loading dose in combination with aspirin compared with ticlopidine in combination with aspirin after coronary stenting: the clopidogrel aspirin stent international cooperative study (CLASSICS). Circulation. 2000;102:624-9.

4. Muller C, Buttner HJ, Petersen J, Roskamm H. A randomized comparison of clopidogrel and aspirin versus ticlopidine and aspirin after the placement of coronary-artery stents. Circulation. 2000;101:590-3.

5. CURE study investigators. The Clopidogrel in Unstable angina to prevent Recurrent Events (CURE) trial programme; rationale, design and baseline characteristics including a meta-analysis of the effects of thienopyridine in vascular disease. Eur Heart J. 2000;21:2033-41.

6. CAPRIE steering committee. A randomised, blinded, trial of clopidogrel versus aspirin in patients at risk of ischaemic events (CAPRIE). Lancet. 1996;348:1329-39.

7. Hongo RH, Ley J, Dick SE, Yee RR. The effect of clopidogrel in combination with aspirin when given before coronary artery bypass grafting. J Am Coll Cardiol. 2002;40:231-7.

8. Yende S, Wunderink RG. Effect of clopidogrel on bleeding after coronary artery bypass surgery. Crit Care Med. 2001;29:2271-5.

9. Kapetanakis EI, Medlam DA, Boyce SW, Haile E, Hill PC, Dullum $\mathrm{MK}$, et al. Clopidogrel administration prior to coronary artery bypass grafting surgery: the cardiologist's panacea or the surgeon's headache. Eur Heart J. 2005;26:576-83.

10. Chu MW, Wilson SR, Novick RJ, Stitt LW, Quantz MA. Does clopidogrel increase blood loss following coronary artery bypass surgery? Ann Thorac Surg. 2004;78:1536-41.

11. Cannon CP, Mehta SR, Aranki SF. Balancing the benefit and risk of oral antiplatelet agents in coronary artery bypass surgery. Ann Thorac Surg. 2005;80:768-79.

12. Multicenter Study of Perioperative Ischemia Research Group. Aspirin and mortality from coronary bypass surgery. $N$ Engl J Med. 2002;347: 1309-17.
13. Raja SG, Dreyfus GD. Impact of off-pump coronary artery bypass surgery on postoperative bleeding: current best available evidence. J Card Surg. 2006;21:35-41.

14. Karmanoukian H, Attuwabi B, Nader ND. Antithrombotic controversies in off-pump coronary bypass. Semin Thorac Cardiovasc Surg. 2005; 17:59-65.

15. Frankel TL, Stamou SC, Lowery RC, Kapetanakis EI, Hill PC, Haile E, et al. Risk factors for hemorrhage-related reexploration and blood transfusion after conventional versus coronary revascularization without cardiopulmonary bypass. Eur J Cardiothorac Surg. 2005;27:494500 .

16. Kapetanakis EI, Medlam DA, Petro KR, Haile E, Hill PC, Dullum $\mathrm{MK}$, et al. Effect of clopidogrel premedication in off-pump cardiac surgery: are we forfeiting the benefits of reduced hemorrhagic sequelae? Circulation. 2006;113:1667-74.

17. Woo YJ, Grand T, Valettas N. Off-pump coronary artery bypass grafting attenuates postoperative bleeding associated with preoperative clopidogrel administration. Heart Surg Forum. 2003;6:282-5.

18. Braunwald E, Antman EM, Beasley JW, Califf RM, Cheitlin MD, Hochman JS, et al. ACC/AHA guideline update for the management of patients with unstable angina and non-ST-segment elevation myocardial infarction 2002: summary article: a report of the American College of Cardiology/American Heart Association Task Force on Practice Guidelines (Committee on the Management of Patients with Unstable Angina). Circulation. 2002;106:1893-900.

19. Gibbs NM, Weightman WM, Thackray NM, Michalopoulos N, Weidmann $C$. The effects of recent aspirin ingestion on platelet function in cardiac surgical patients. J Cardiothorac Vasc Anesth. 2001;15:55-9.

20. von Heymann C, Redlich U, Moritz M, Sander M, Vargas Hein O, Grubitzsch $\mathrm{H}$, et al. Aspirin and clopidogrel taken until 2 days prior to coronary artery bypass graft surgery is associated with increased postoperative drainage loss. Thorac Cardiovasc Surg. 2005;53:341-5.

21. Wan IY, Arifi AA, Wan S, Yip JH, Sihoe AD, Thung KH, et al. Beating heart revascularization with or without cardiopulmonary bypass: evaluation of inflammatory response in a prospective randomized study. J Thorac Cardiovasc Surg. 2004;127:1624-31.

22. Johansson-Synnergren M, Nilsson F, Bengtsson A, Jeppsson A, Wiklund L. Off-pump CABG reduces complement activation but does not significantly affect peripheral endothelial function: a prospective randomized study. Scand Cardiovasc J. 2004;38:53-8.

23. Bhatt DL, Chew DP, Hirsch AT, Ringleb PA, Hacke W, Topol EJ. Superiority of clopidogrel versus aspirin in patients with prior cardiac surgery. Circulation. 2001;103:363-8.

24. Fox KA, Mehta SR, Peters R, Zhao F, Lakkis N, Gersh BJ, et al. Benefits and risks of the combination of clopidogrel and aspirin in patients undergoing surgical revascularization for non-ST-elevation acute coronary syndrome: the Clopidogrel in Unstable angina to prevent Recurrent ischemic Events (CURE) trial. Circulation. 2004;110: 1202-8.

25. Clopidogrel in Unstable Angina to Prevent Recurrent Events Trial Investigators. Effects of clopidogrel in addition to aspirin in patients with acute coronary syndromes without ST-segment elevation. $N$ Engl J Med. 2001;345:494-502.

26. Mariani MA, Gu YJ, Boonstra PW, Grandjean JG, van Oeveren W, Ebels T. Procoagulant activity after off-pump coronary operation: is the current anticoagulation adequate? Ann Thorac Surg. 1999;67: $1370-5$. 